\title{
Endocan and Asymmetric Dimethylarginine as an Etiological Indicator in the Maternal and Umbilical Cord Serum in Pre-Eclampsia
}

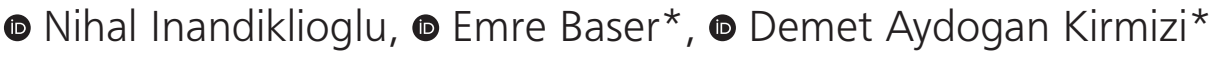 \\ Yozgat Bozok University Faculty of Medicine, Department of Medical Biology, Yozgat, Turkey \\ *Yozgat Bozok University Faculty of Medicine, Department of Gynecology and Obstetrics, Yozgat, Turkey
}

\section{Abstract}

\begin{abstract}
Aim: Preeclampsia is a pregnancy-specific disease of unknown etiology. This study was planned to determine the place of asymmetric dimethylarginine ( $\mathrm{N}, \mathrm{N}$-dimethylarginine, ADMA) and endothelial cell specific molecule-1 (ESM1, endocan) levels in etiology. The aim of this study was to determine ADMA and endocan levels in maternal and fetal umbilical cord serum of patients with preeclampsia and to evaluate them with clinical data.
\end{abstract}

Methods: This case-control study was conducted between June and December 2020. The clinical and demographic characteristics of the participants were evaluated in the department of obstetrics and gynecology. Thirty-tree women with preeclampsia and 55 healthy women in the same age group were included in our study. Serum ADMA and endocan values were determined by the ELISA method.

Results: Maternal and umbilical cord ADMA levels in the preeclampsia group were statistically significantly higher than the control group ( $p=0.001, p=0.001$, respectively). Likewise, the levels of the umbilical cord and maternal serum endocan were statistically significantly higher in the preeclampsia group compared to the control group ( $p=0.001, p=0.037$, respectively).

Conclusion: We found that ADMA and endocan molecules associated with endothelial dysfunction in the pathogenesis of preeclampsia significantly increased in maternal and umbilical cord serum.

Key words: N, N-dimethylarginine, preeclampsia, pregnancy, proteoglycans, umbilical cord

\section{Introduction}

Preeclampsia is the accompanying of proteinuria to new-onset hypertension in pregnancy. In some preeclampsia, proteinuria may not evidently develop. Therefore, preeclampsia is the presence of one of the findings of proteinuria accompanying gestational hypertension or gestational hypertension accompanied by at least one of thrombocytopenia (platelet $<100,000$ / $\mathrm{mm}^{3}$ ), renal failure (creatinine doubled from baseline or $>1.1 \mathrm{mg} / \mathrm{dL}$ ), liver findings [Alanine aminotransferase (ALT) or aspartate transaminase (AST) doubling the normal], cerebral findings (headache, seizure, visual disturbances) or pulmonary edema findings $(1,2)$.
Asymmetric dimethylarginine (ADMA) is an amino acid naturally occurring in plasma and is an endogenous nitric oxide synthase (NOS) inhibitor (3). Nitric oxide (NO) is a free radical, synthesized by the NOS from L-arginine. NO regulates endothelium-dependent vasodilation, proliferation of smooth muscle cells in the vascular wall, aggregation by platelet adhesion and monocyte adhesion inhibition. It also plays a role in maintaining vascular balance and blood supply to the organs (4). Since NO is a major endothelial vasoactive mediator, ADMA is thought to play a key role in endothelial dysfunction. The endocan molecule, also known as endothelial cell-specific molecule-1 (ESM-1), is a proteoglycan synthesized from endothelial cells and detectable in serum. It is found especially in lung, kidney

Address for Correspondence: Nihal Inandiklioglu, Yozgat Bozok University Faculty of Medicine, Department of Medical Biology, Yozgat, Turkey Phone: +90 5304688437 E-mail: nihal.inandiklioglu@yobu.edu.tr ORCID: orcid.org/ 0000-0003-2813-3406 Received: 19.02.2021 Accepted: 28.04.2021 
cells, adipocyte and endothelium (5). ADMA is associated with many conditions such as intracellular signaling, differentiation, migration, proliferation and adhesion of different cell types. Increased release of ADMA in the tissue or its level in the blood reflects endothelial activation and neovascularization, which indicates inflammation and tumor progression (6).

The main problem in preeclampsia is endothelial cell damage due to increased inflammatory response. Endothelial cell damage and subsequent endothelial dysfunction make sense of clinical findings detected in preeclampsia disease. The cause of the symptoms that play a role in preeclampsia clinic is diffuse endothelial dysfunction (7). It is thought that the molecule NO has a key role in the regulation of endothelial function. The aim of this study was to evaluate the maternal and fetal umbilical cord serum levels of ADMA and endocan molecules, which are associated with endothelial dysfunction and have different results in the literature, and to investigate the relationship between preeclampsia clinical effects and these parameters.

\section{Methods}

\section{Study Population}

This case-control study was conducted between June and December 2020. The clinical and demographic characteristics of the participants were evaluated in the department of obstetrics and gynecology. This study was approved by the Ethics Review Board of Yozgat Bozok University Faculty of Medicine (document no: 2017KAEK-189_2020.06.23_08). The study was carried out in accordance with the principles of medical research provided by the Helsinki Declaration. Written informed consent was obtained from each participant. Preeclampsia diagnosis after the $20^{\text {th }}$ week of gestation was made by blood pressure measurements taken at least four hours intervals and determined by systolic pressure above 140 $\mathrm{mmHg}$ and diastolic pressure above $90 \mathrm{~mm} \mathrm{Hg}$ and also by measuring proteinuria in 24-hour urine $\geq 0.3 \mathrm{~g}$; proteinuria/ creatinine ratio $\geq 0.3$ or $\geq+1$ proteinuria in spot urine sample (8). Diabetes mellitus, thyroid diseases, cardiovascular diseases, chronic renal failure, hyperprolactinemia, Cushing's syndrome, congenital adrenal hyperplasia and 21-hydroxylase deficiency were accepted as exclusion criteria for the preeclampsia group. The control group was composed of normotensive 18-40 years old 370/7$406 / 7$ w healthy singleton pregnant women. Body mass index (BMI) was calculated by dividing body weight by the square of height $\left(\mathrm{kg} / \mathrm{m}^{2}\right)$. Patients' age, gravidity, parity, gestational weeks, systolic/diastolic blood pressure levels, protein levels in spot urine protein, hemoglobine, platelet counts, creatinine, urea, liver function markers (AST, ALT, lactate dehydrogenase), angiogenic and antiangiogenic factors sEng, sFlt and Pgf levels were recorded. Gestational weeks were determined according to the last menstrual period confirmed by ultrasonography.

\section{Determination of Serum ADMA and Endocan Levels}

Venous blood samples were taken from the participants before giving birth and taken from the umbilical cord at birth. Venous blood samples were collected in a 5 $\mathrm{mL}$ serum-separating vacuum tube. Blood samples were collected and centrifuged for $10 \mathrm{~min}$ at $2.000 \mathrm{~g}$. The supernatant was quickly removed and kept frozen at -80 ${ }^{\circ} \mathrm{C}$ until the assays were performed. Serum ADMA (cat. no REA201/96, BioVendor, Czech Republic) and Endocan (cat. no E3160Hu, Bioassay Technology Laboratory, China) levels were measured with commercially available enzymelinked immune sorbent assay (ELISA) kits, with a minimum detectable concentration of $0.4 \mu \mathrm{mol} / \mathrm{L}$ and $5 \mathrm{ng} / \mathrm{L}$, respectively, according to the manufacturer's instructions. Optical density values for samples and standard samples were detected on Thermo Scientific (USA) Multiscan Go Microplate Reader ELISA reader at $450 \mathrm{~nm}$. The results are presented as $\mu \mathrm{mol} / \mathrm{L}$ and $\mathrm{ng} / \mathrm{mL}$.

\section{Statistical Analysis}

Statistical analysis was performed using SPSS (version 20, SPSS Inc., Chicago, IL, USA). For each continuous variable, normality was checked by Kolmogorov-Smirnov and Shapiro-Wilk tests. The categorical variables between the groups were analyzed by using the chi-square test or Fisher's Exact test. Comparisons between groups were applied using Student's t-test (normally distributed data) and Mann-Whitney $U$ test (not normally distributed data). A multivariate logistic regression analysis was performed

\begin{tabular}{|c|c|c|c|}
\hline & Control $(n=55)$ & $\begin{array}{l}\text { Preeclampsia } \\
(\mathrm{n}=33)\end{array}$ & $p$ \\
\hline Age (year) & $29.8 \pm 4.8$ & $29.3 \pm 6.3$ & 0.650 ** \\
\hline BMI $\left(\mathrm{kg} / \mathrm{m}^{2}\right)$ & $29.5 \pm 4.1$ & $29.1 \pm 3.3$ & $0.761^{*}$ \\
\hline Gravida & $2.8 \pm 1.8$ & $3.3 \pm 2.2$ & $0.423^{*}$ \\
\hline Parity & $1.8 \pm 1.5$ & $1.8 \pm 1.9$ & $0.557^{\star}$ \\
\hline Gestational week & $37.5 \pm 1.1$ & $33.3 \pm 4.3$ & $0.001 *$ \\
\hline $\begin{array}{l}\text { Gender } \\
\text { Male (n) (\%) } \\
\text { Female (n) (\%) }\end{array}$ & $\begin{array}{l}23(44.2 \%) \\
29(55.8 \%)\end{array}$ & $\begin{array}{l}20(51.3 \%) \\
19(48.7 \%)\end{array}$ & $0.505^{\star}$ \\
\hline $\begin{array}{l}\text { Neonatal weight } \\
\text { (g) }\end{array}$ & $3203 \pm 553.9$ & $2252.8 \pm 1017.6$ & $0.001 *$ \\
\hline $\begin{array}{l}\text { Systolic pressure } \\
(\mathrm{mmHg})\end{array}$ & $109.8 \pm 14.7$ & $135.1 \pm 24.5$ & $0.001 *$ \\
\hline $\begin{array}{l}\text { Diastolic pressure } \\
(\mathrm{mmHg})\end{array}$ & $70.4 \pm 9.7$ & $86.3 \pm 14.3$ & $0.001 *$ \\
\hline
\end{tabular}




\begin{tabular}{|c|c|c|c|}
\hline & $\begin{array}{l}\text { Control } \\
(n=55)\end{array}$ & $\begin{array}{l}\text { Preeclampsia } \\
(\mathrm{n}=33)\end{array}$ & $\mathbf{p}$ \\
\hline AST (U/L) & $17.3 \pm 8.4$ & $24.9 \pm 20.5$ & $0.019^{*}$ \\
\hline $\operatorname{ALT}(U / L)$ & $15.4 \pm 14.2$ & $15.2 \pm 12.6$ & $0.533^{*}$ \\
\hline BUN (mg/dL) & $7.5 \pm 2.5$ & $19.4 \pm 10.6$ & $0.001 *$ \\
\hline CRE (U/L) & $0.5 \pm 0.1$ & $0.6 \pm 0.2$ & $0.001 *$ \\
\hline $\mathrm{LDH}(\mathrm{U} / \mathrm{L})$ & $198.7 \pm 26.6$ & $304.3 \pm 167.4$ & $0.001^{*}$ \\
\hline $\begin{array}{l}\text { Spot urine protein } \\
(\mathrm{mg} / \mathrm{dL})\end{array}$ & $0 \pm 0$ & $1.5 \pm 2$ & $0.001 *$ \\
\hline 24-h urine (mg/day) & - & $1500.9 \pm 1378.6$ & - \\
\hline Hemoglobin $(\mathrm{g} / \mathrm{dL})$ & $11.6 \pm 1.4$ & $11.8 \pm 1.8$ & $0.488^{* *}$ \\
\hline Hematocrite (\%) & $34.1 \pm 3.9$ & $35.2 \pm 4.5$ & 0.291 ** \\
\hline Platelets $\left(10^{3} / \mathrm{mm}^{3}\right)$ & $234.1 \pm 41.2$ & $205.9 \pm 64.2$ & $0.015^{* *}$ \\
\hline $\begin{array}{l}\text { Maternal ADMA } \\
(\mu \mathrm{mol} / \mathrm{L})\end{array}$ & $0.8 \pm 0.2$ & $1.2 \pm 1.1$ & $0.001 *$ \\
\hline $\begin{array}{l}\text { Umbilical cord } \\
\text { ADMA ( } \mu \mathrm{mol} / \mathrm{L})\end{array}$ & $1.2 \pm 2.2$ & $1.5 \pm 0.5$ & $0.001^{*}$ \\
\hline $\begin{array}{l}\text { Maternal Endocan } \\
(\mathrm{ng} / \mathrm{mL})\end{array}$ & $2.7 \pm 1.1$ & $3.1 \pm 0.5$ & $0.037^{*}$ \\
\hline $\begin{array}{l}\text { Umbilical cord } \\
\text { Endocan (ng/mL) }\end{array}$ & $3.7 \pm 1.9$ & $4.9 \pm 0.8$ & $0.001 *$ \\
\hline \multicolumn{4}{|c|}{$\begin{array}{l}\text { Values are presented as mean } \pm \text { standard deviation. }{ }^{*} \text { Mann-Whitney } U \text { test, } \\
{ }^{* *} \text { Independent samples t-test. ALT: Alanine aminotransferase, AST: Aspartate } \\
\text { aminotransferase, BUN: Blood urea nitrogen, CRE: Creatinine, LDH: Lactate } \\
\text { dehydrogenase, 24-h urine: } 24 \text { hours urine }\end{array}$} \\
\hline
\end{tabular}

to determine independent risk factors. A p-value of less than 0.05 was considered significant.

\section{Results}

The demographic characteristics of the groups in our study were presented in Table 1. When the groups were compared statistically, there was no significant difference in age and BMI averages, but systolic pressure and diastolic pressure were significantly higher in the preeclampsia group $(p<0.001)$.

Biochemical parameters and ELISA results of the study groups were presented in Table 2. Maternal serum and umbilical cord serum ADMA values were significantly higher in the preeclampsia group compared to the control group ( $p<0.001$ ). Likewise, the umbilical cord and maternal serum endocan levels were found to be significantly higher in the preeclampsia group $(p<0.05)$ (Table 2 ).

In the multivariate logistic regression analysis, the most important independent risk factor predicting preeclampsia was maternal ADMA [Odds ratio (OR): 6.8, 95\% confidence interval (Cl): 1.7-8.9], and the other independent risk factor was determined as cord endocan (OR: 3.7, 95\% Cl: 2.1-5.5) (Table 3). This result indicated that the rising of maternal ADMA increases the risk of preeclampsia 6.8 times, and the rising of cord endocan increases the risk of preeclampsia 3.7 times.
Table 3. Multivariate logistic regression analysis results of ADMA and endocan values

\begin{tabular}{|l|l|l|l|l|l|l|}
\hline & B & SE & $\mathbf{p}$ & OR & \multicolumn{2}{|l|}{$\mathbf{9 5 \%}$ Cl } \\
\cline { 5 - 8 } & & & Lower & Upper \\
\hline Maternal ADMA ( $\mu \mathrm{mol} / \mathrm{L})$ & 4.6 & 3.7 & $\mathbf{0 . 0 0 1}$ & 6.8 & 1.7 & 8.9 \\
\hline $\begin{array}{l}\text { Umbilical cord ADMA } \\
(\mu \mathrm{mol} / \mathrm{L})\end{array}$ & 3.6 & 0.2 & 0.076 & 1.5 & 0.8 & 2.5 \\
\hline $\begin{array}{l}\text { Umbilical cord endocan } \\
(\mathrm{ng} / \mathrm{mL})\end{array}$ & 1.4 & 0.5 & $\mathbf{0 . 0 1 1}$ & 3.7 & 2.1 & 5.5 \\
\hline $\begin{array}{l}\text { Maternal endocan (ng/ } \\
\text { mL) }\end{array}$ & 0.4 & 0.6 & 0.200 & 1.2 & 0.8 & 6.8 \\
\hline $\begin{array}{l}\text { ADMA: Asymmetric dimethylarginine, B: Regression coefficient, Cl: Confidence } \\
\text { interval, OR: Odds ratio, SE: Standart error }\end{array}$ \\
\hline
\end{tabular}

\section{Discussion}

Endothelial dysfunction is accepted to be the basis of the pathogenesis of preeclampsia (9). It is a disease with vasospasm due to endothelial damage, activation of the coagulation system, edematous ischemic and thrombotic sequelae that progresses negatively in humoral and local control affecting blood pressure and fluid volume (10). Maternoplacental ischemic environment occurring after defective placentation causes placental factors to be released and pass into the maternal circulation. This condition initiates maternal endothelial cell damage and dysfunction. The vasodilator effect is disrupted by the anticoagulant effect of the intact endothelium, the balance of prostaglandin production and the release of $\mathrm{NO}$ $(9,11,12)$. In this study, the maternal and umbilical cord serum levels of NOS inhibitor ADMA and a prostaglandin endocan were evaluated in preeclampsia patients. ADMA and endocan levels were found to be high in the maternal and umbilical cord in the preeclampsia group. Serum ADMA and endocan levels can be considered as independent risk factors for preeclampsia.

ADMA levels have been associated with many diseases such as renal diseases, Alzheimer's, liver failure, cirrhosis, cardiovascular diseases, diabetes and preeclampsia. The inhibition of NO synthesis by ADMA causes endotheliumdependent vasodilation (3). Increased levels of ADMA have been associated with endothelial dysfunction, thus preeclampsia (13). In the study conducted by Fickling et al. (14) ADMA was associated with preeclampsia and the ADMA level was found to be significantly higher in the preeclampsia group compared to healthy pregnant women. Data supporting the same result were presented and various authors emphasized that increasing ADMA levels may play an important role in the pathogenesis of preeclampsia. These data indicated that high circulating ADMA concentration in pregnant women could be defined as a potential biomarker of preeclampsia (15-17). It has also been reported that the ADMA level decreases during normal pregnancy, decreases to a minimum at 
the end of the first trimester and then increases with the gestational age (18). On the other hand, it was determined that serum ADMA levels of pregnant women who developed preeclampsia were high in the first trimester and in the second trimester (19), and serum ADMA levels of pregnant women who did not develop preeclampsia and had Small for Gestational Age were normal (20). It was demonstrated that the increase in ADMA levels developed before the clinical findings of preeclampsia at 23 weeks of gestation (21). In preeclampsia studies performed in the umbilical cord serum, there are different data in the literature as in maternal serum ADMA results. Albayrak et al. (22) brought out no change in maternal serum ADMA level of the preeclampsia group, while they found the umbilical cord serum ADMA level higher than controls. In another study, both maternal serum and umbilical cord serum levels were detected to be higher in the preeclampsia group compared to the control (23). Even in the preeclampsia group, serum ADMA levels of the umbilical cord were noticed to be significantly higher in the severe preeclampsia group compared to the mild preeclampsia group (13).

Endocan is a proteoglycan secreted from vascular endothelia cells, indicative of endothelial function. It has been propounded that serum concentrations are elevated in conditions associated with endothelial activation or dysfunction. Studies have suggested that endocan can be a marker in many diseases such as tissue damage, angiogenesis, oncogenesis, inflammation, and sepsis (24). When we looked at the studies conducted with preeclampsia pregnant women in the literature, there were studies reporting that serum endocan levels were statistically higher than healthy pregnant women $(5,10,11)$. In a meta-analysis study involving 451 preeclampsia pregnant women, it was determined that the level of endocan was higher in pregnant women with preeclampsia compared to normal healthy pregnant women (25). However, in other studies, no difference was found between serum endocan levels in the preeclampsia and the control groups $(26,27)$. Even though the endocan protein and its expression in the maternal placenta were studied out to be higher than the control, no significant difference was found in the maternal serum level (27). A factor affecting the serum endocan level is the gestational week and it has been reported that as the gestational week increases, the serum endocan level decreases (26). A similar result was determined in patients with early onset preeclampsia, and no significant result was found (28). Moreover, no significant difference was observed between the groups with early and late preeclampsia and normotensive pregnant women (29). Schuitemaker et al. (30) highlighted that the endocan molecule has an angiogenic function in the first and second trimesters; therefore, the endocan level may be low in early-onset preeclampsia because angiogenesis is disrupted. A study on the endocan level in the fetal umbilical cord in preeclampsia patients is not included in the literature. In one of the existing studies, the umbilical cord endocan level in pregnancies complicated by intrauterine growth restriction (31) and in the other one, the umbilical cord endocan level was evaluated according to the delivery type (32). In this study, ADMA and endocan levels were found to be high in the maternal and umbilical cord in the preeclampsia group. Differences in the results of the studies may be based on the fact that they were performed without subgrouping, different samples (plasma, serum or placenta) were studied, and the number of different pregnant women.

\section{Study Limitations}

Our study has a few limitations. First, the sample size is relatively small. Second, there may be different ELISA kits used. However, evaluating both umbilical cord and maternal serum levels together is a factor that strengthens our study. At the same time, evaluating these two molecules, which are important in etiology, makes the study valuable.

\section{Conclusion}

In conclusion, the most important reasons for the different results between studies on ADMA and endocan include the difference in gestational week, the difference in tissue studied and the sample number. In future studies, expanding the sample size, measurements of each trimester of pregnancy, expression, protein and serum levels of maternal, placenta and umbilical cord samples and dividing preeclampsia into different subgroups according to its severity will provide more confirmed results.

\section{Authorship Contributions}

Concept: N.I., E.B., Design: N.I., E.B., Data Collection or Processing: N.I., E.B., D.A.K., Analysis or Interpretation: N.I., Literature Search: N.I., E.B., D.A.K., Writing: N.I., D.A.K.

Conflict of Interest: No conflict of interest was declared by the authors.

Financial Disclosure: The authors declared that this study received no financial support.

\section{References}

1. Hypertension in pregnancy. Report of the American College of Obstetricians and Gynecologists' Task Force on Hypertension in Pregnancy. Obstet Gynecol 2013;122:1122-31.

2. Nirupama R, Divyashree S, Janhavi P, Muthukumar SP, Ravindra PV. Preeclampsia: Pathophysiology and management. J Gynecol Obstet Hum Reprod 2021;50:101975. 
3. Böger RH, Vallance $P$, Cooke JP. Asymmetric dimethylarginine (ADMA): a key regulator of nitric oxide synthase. Atheroscler Suppl 2003;4:1-3.

4. Guerby P, Tasta O, Swiader A, et al. Role of oxidative stress in the dysfunction of the placental endothelial nitric oxide synthase in preeclampsia. Redox Biol 2021;40:101861.

5. Hentschke MR, Lucas LS, Mistry HD, Pinheiro da Costa BE, Poli-de-Figueiredo CE. Endocan-1 concentrations in maternal and fetal plasma and placentae in pre-eclampsia in the third trimester of pregnancy. Cytokine 2015;74:152-6.

6. Leite AR, Borges-Canha M, Cardoso R, Neves JS, CastroFerreira R, Leite-Moreira A. Novel Biomarkers for Evaluation of Endothelial Dysfunction. Angiology 2020;71:397-410.

7. Feng $X$, Liu $Y$, Zhang $Y$, et al. New views on endothelial dysfunction in gestational hypertension and potential therapy targets. Drug Discov Today 2021;26:1420-36.

8. Steegers EA, von Dadelszen P, Duvekot JJ, Pijnenborg R. Preeclampsia. Lancet 2010;376:631-44.

9. Mauro AK, Khurshid N, Berdahl DM, et al. Cytokine concentrations direct endothelial function in pregnancy and preeclampsia. J Endocrinol 2021;248:107-17.

10. Adekola $H$, Romero R, Chaemsaithong $P$, et al. Endocan, a putative endothelial cell marker, is elevated in preeclampsia, decreased in acute pyelonephritis, and unchanged in other obstetrical syndromes. J Matern Fetal Neonatal Med 2015;28:1621-32.

11. Cakmak M, Yilmaz H, Bağlar E, et al. Serum levels of endocan correlate with the presence and severity of pre-eclampsia. Clin Exp Hypertens 2016;38:137-42.

12. Cunningham FG. Hypertensive disorders. In: F. Gary Cunningham, Kenneth J. Leveno, Steven L. Bloom, et al. editors. Williams Obstetrics. 24th ed. New York: Mc Graw Hill; 2014. p. 728-79.

13. Pettersson A, Hedner T, Milsom I. Increased circulating concentrations of asymmetric dimethyl arginine (ADMA), an endogenous inhibitor of nitric oxide synthesis, in preeclampsia. Acta Obstet Gynecol Scand 1998;77:808-13.

14. Fickling SA, Williams D, Vallance P, Nussey SS, Whitley GS. Plasma concentrations of endogenous inhibitor of nitric oxide synthesis in normal pregnancy and pre-eclampsia. Lancet 1993;342:242-3.

15. Böger RH, Diemert A, Schwedhelm E, Lüneburg N, Maas $\mathrm{R}$, Hecher $\mathrm{K}$. The role of nitric oxide synthase inhibition by asymmetric dimethylarginine in the pathophysiology of preeclampsia. Gynecol Obstet Invest 2010;69:1-13.

16. Yuan J, Wang $X$, Xie $Y$, et al. Circulating asymmetric dimethylarginine and the risk of preeclampsia: a meta-analysis based on 1338 participants. Oncotarget 2017;8:43944-52.

17. Meng W, Zhanashunbayaer, E L, Li R. Association between asymmetric dimethylarginine level and preeclampsia: a metaanalysis. Int J Clin Exp Med 2017;10:8720-7.

18. Holden DP, Fickling SA, Whitley GS, Nussey SS. Plasma concentrations of asymmetric dimethylarginine, a natural inhibitor of nitric oxide synthase, in normal pregnancy and preeclampsia. Am J Obstet Gynecol 1998;178:551-6.

19. Bian Z, Shixia C, Duan T. First-Trimester Maternal Serum Levels of sFLT1, PGF and ADMA Predict Preeclampsia. PLoS One 2015;10:0124684.

20. Speer PD, Powers RW, Frank MP, Harger G, Markovic N, Roberts $J M$. Elevated asymmetric dimethylarginine concentrations precede clinical preeclampsia, but not pregnancies with small-for-gestational-age infants. Am J Obstet Gynecol 2008;198:112.e1-7.

21. Savvidou MD, Hingorani AD, Tsikas $D$, Frölich JC, Vallance $P$, Nicolaides $\mathrm{KH}$. Endothelial dysfunction and raised plasma concentrations of asymmetric dimethylarginine in pregnant women who subsequently develop pre-eclampsia. Lancet 2003;361:1511-7.

22. Albayrak $M$, Öncül $M$, Uludağ $S$, et al. Comparison of maternal serum and umbilical cord concentrations of nitric oxide and asymmetric-dimethyl-arginine in pre-eclamptic and uncomplicated pregnancies. J Exp Clin Med 2013;30:125-8.

23. Gumus E, Atalay MA, Cetinkaya Demir B, Sahin Gunes E. Possible role of asymmetric dimethylarginine (ADMA) in prediction of perinatal outcome in preeclampsia and fetal growth retardation related to preeclampsia. J Matern Fetal Neonatal Med 2016;29:3806-11.

24. Yilmaz MI, Siriopol D, Saglam $M$, et al. Plasma endocan levels associate with inflammation, vascular abnormalities, cardiovascular events, and survival in chronic kidney disease. Kidney Int 2014;86:1213-20.

25. Lan X, Liu Z. Circulating endocan and preeclampsia: a metaanalysis. Biosci Rep 2020;40:BSR20193219.

26. Yuksel MA, Tuten $A$, Oncul $M$, et al. Serum endocan concentration in women with pre-eclampsia. Arch Gynecol Obstet 2015;292:69-73.

27. Chang $X$, Bian $Y$, Wu $Y$, Huang $Y$, Wang $K$, Duan T. Endocan of the maternal placenta tissue is increased in pre-eclampsia. Int J Clin Exp Pathol 2015;8:14733-40.

28. Ovayolu A, Karaman E, Turgut A, Guler S, Bostancieri N. Maternal serum endothelial cell-specific molecule-1 level and its correlation with severity of early-onset preeclampsia. J Obstet Gynaecol 2020:1-6.

29. Lopes ACDS, Martins SR, Dusse LMS, Pinheiro MB, Alpoim PN. Are Endocan Plasma Levels Altered in Preeclampsia? Rev Bras Ginecol Obstet 2021;43:232-4.

30. Schuitemaker J, Woudenberg J, Wijbenga G, Scherjon S, van Pampus M, Faas M. PP077. New prognostic marker for the risk to develop early-onset preeclampsia. Pregnancy Hypertens 2013;3:95-6.

31. Szpera-Gozdziewicz A, Kosicka K, Gozdziewicz T, et al. Maternal Serum Endocan Concentration in Pregnancies Complicated by Intrauterine Growth Restriction. Reprod Sci 2019;26:370-6.

32. Aksoy M, Aksoy AN, Laloglu E, Dostbil A, Celik MG. Umbilical cord blood endocan levels according to the delivery mode. Clin Exp Obstet Gynecol 2015;42:776-80. 